\title{
PESQUISA EM SALA DE AULA: A PRÁTICA DE TRADUÇÃ̃ NA PRÁTICA
}

\section{Leila Cristina de Melo Darin*}

RESUMO: O presente artigo tem por meta tecer algumas considerações sobre a situação de ensino-aprendizagem da tradução no contexto universitário, examinando-a a partir da ótica da pesquisa etnográfica. Nosso foco central é o processo de confecção de traduçōes em sala de aula e nossa ambição é estimular uma reflexão que possa contribuir para o debate sobre a formação de tradutores.

UNITERMOS: Pesquisa etnogräfica; processo de ensinoaprendizagem; teoria e prătica da tradução.

ABSTRACT: The aim of this article is to present some considerations on the process of teaching and learning translation at university level by examining it from the viewpoint of ethnographic research. Ourfocus is the process of producing translations within the classroom situation and it is our intention to stimulate reflection that may lead towards a fruitful debate on the training of translators.

KEYWORDS: Ethnographic research; teaching and learning process; translation theory and practice.

É certamente animador, para todo estudioso dos fenômenos envolvidos na traduçāo, o crescente número de publicaçōes referentes à área nos últimos anos. Contudo, apesar da variedade de ângulos em que a tradução tem sido abordada, observa-se,

(*) Pontificia Universidade Católica de São Paulo.

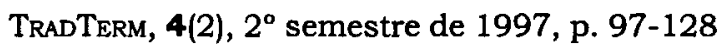


ainda hoje, uma carência de estudos que enfocam diretamente o processo de ensino-aprendizagem da tradução. Na posição de professores responsáveis pela formação de tradutores em nivel de Graduação - em particular da disciplina Prática de Tradução no curso de Letras da PUC-SP -, acreditamos ser de vital importância refletir sobre os vários fatores que interagem no âmbito especifico da aula de Prática de Traduçāo (PT) para que possa haver uma visão critica do processo, que possibilite, como objetivo final, o aprimoramento đas condições de ensino e a formaçāo de profissionais mais competentes e conscientes de seu oficio.

Em pesquisa realizada anteriormente com o apoio do CEPE da PUC-SP $(1995)^{1}$, pudemos constatar que grande parte das dificuldades tradutórias apresentadas pelos alunos-tradutores decorria de atitudes e conceitos vinculados a concepçōes, a nosso ver equivocadas, do que é tradução. Neste estudo, nossa proposta é prosseguir examinando a situaçāo de ensino-aprendizagem de prática de tradução e relacionar nossas descobertas às conclusōes a que chegamos na investigação de 1995. Para tal, assumimos o papel de pesquisadores de nossa própria prática didática e, com auxilio de instrumentos de observação e análise sugeridos pela pesquisa de base etnográfica (Allwright \& Bailey, 1991), passamos a construir uma leitura das aulas de PT com base na concepção de tradução que definiremos a seguir.

\section{A traduçāo e suas questões}

Tradicionalmente, a atividade tradutória tem sido definida em função de alguns tópicos que se encontram intrinsecamente ligados: a relação de fidelidade que a tradução "deve manter" com o texto fonte; a questão da superioridade do texto na lingua fonte e a conseqüente inferioridade em que é relegada a tradução; e o perfil do tradutor como "intermediário imparcial" ou "mera ponte" entre duas linguas e culturas. A visão subjacente a estas questões tem sido desafiada, entre outros, pelo pensa-

(1) Esta pesquisa gerou o artigo que foi publicado na revista Claritas, n. 3, 1997.

TRADTERM, 4(2), $2^{\circ}$ semestre de 1997 , p. 97-128 
mento pós-estruturalista cujas implicações para a traduçāo foram divulgadas em nossos ambientes acadêmicos a partir do livro Oficina de Tradução (Arrojo, 1986). Nesse livro, Arrojo propōe uma redefiniçāo da atividade tradutória visando tirar o tradutor $\mathrm{da}$ "margem" em que lhe confinavam as teorias tradicionais $e$ situando-o como leitor-interventor e como produtor de textos. Dentro dessa perspectiva, a tradução deixa de ser uma tarefa de "segunda ordem", ato que se resume a "trazer intacto" um texto prévio para outro idioma, e passa a constituir-se uma atividade fundamentalmente critica e renovadora. Assim redimensionado, o ato tradutório não é mais entendido como cópia, substituição, transferência ou decodificação de significados preestabelecidos, mas passa a ser visto sob a ótica da criação, da transformação, de uma reescritura que se nutre do conjunto de crenças e valores do(a) tradutor(a) e da(s) comunidade(s) com a(s) qual(is) se relaciona.

Como ressalta Arrojo, em "A tradução passada a limpo", a consciência do tradutor sobre seu papel social e sobre o processo que vive acarreta mudanças em todos os niveis do trabalho tradutório:

Quanto mais visivel se tornar a presença do tradutor no texto traduzido, quanto maior sua visão - ou sua "visibilidade" acerca do processo do qual é agente e promotor, menores serāo as chances de que seja ignorado, marginalizado e indignamente remunerado. Assim, serão maiores as probabilidades de que assuma suas responsabilidades autorais e de que realize um trabalho mais apurado e meticuloso, como resultado de uma reflexão e de uma pesquisa mais conscientes. Afinal, quem se percebe "visivel", pode reconhecer-se no que faz $e$ reivindicar o reconhecimento daqueles que utilizam e avaliam seu trabalho. (1993, p. 85)

As implicações destas considerações para o ensino da tradução sāo inúmeras e extremamente positivas na medida em realçam a necessidade do desenvolvimento da percepção crítica do tradutor e de seu papel na sociedade - aspectos amplamente enfatizados nos objetivos do curso de Tradução da PUC-SP. Res- 
ta investigar de que maneira estas consideraçōes se presentificam no âmbito do ensino da tradução, isto é, de que forma se articulam ao trabalho prático realizado pelos futurós tradutores em sua relação com o professor e os colegas nas aulas de Prática de Tradução que ministramos. Para alcançar este objetivo, utilizaremos a pesquisa de base etnográfica, tal como a concebemos abaixo.

\section{A sala de aula como ponto de reflexão}

Assim como acreditamos ser impossivel o tradutor reproduzir o texto de partida de maneira "isenta" e "objetiva" - pois inevitavelmente deixa impressa no texto traduzido a marca de sua diferença, de sua subjetividade - também não é possivel que o professor-pesquisador examine a situaçāo de ensino na qual está engajado de forma "neutra" e "imparcial". A observação e a percepção estāo irremediavelmente impregnadas pelo olhar do pesquisador, que nāo está desvinculado do objeto que procura analisar. Assim, toda a investigação é produto da interação entre sujeito e objeto, fato que a pesquisa de base etnográfica leva em consideraçāo em sua proposta ao descrever o comportamento humano em ambientes "naturais" (em oposição، a ambientes "artificiais" ou "controlados"). Como define Watson-Gegeo,

... ethnography is the study of people's behaviour in naturally occurring, ongoing settings, with a focus on the cultural interpretation of behaviour...The ethnographer's goal is to provide a description and an interpretative-explanatory account of what people do in a setting (such as a classroom, neighbourhood, or community), the outcome of their interactions, and the way they understand what they are doing (the meaning interactions have for them). (1988, p. 576)

Neste sentido, podemos afirmar que tanto a descrição dos fatos sociais feita pelo etnógrafo quanto a reprodução textual realizada pelo tradutor são atos interpretativos que se materializam através do filtro seletivo de um sujeito. Ciente disso, e para 
não se limitar ao contorno restrito de sua observação particular, o etnógrafo procura enriquecer sua visāo da situação observada acrescentando a ela outros pontos de vista, outros instrumentos de análise, também marcados por ângulos interpretativos. Ao levar em conta o fator da subjetividade, a pesquisa de base etnográfica impōe a necessidade de triangular os dados coletados de várias maneiras: por diários, questionários, entrevistas, gravaçōes em áuđio ou video. A respeito desse tipo de pesquisa, Cavalcanti e Lopes ressaltam que:

Desta maneira a assim chamada subjetividade inerente a estes tipos de dados adquire uma natureza intersubjetiva ao se levar em conta várias subjetividades - ou várias maneiras de olhar para o mesmo objeto de investigaçāo - na tarefa de interpretaçäo dos dados, aumentando assim sua confiabilidade. (1991, p. 139)

Em nosso estudo, para investigar a situação de ensinoaprendizagem nas aulas de Prática de Tradução, utilizamos a perspectiva do professor como observador da situação de ensino (através de diários) e agregamos a ela a perspectiva dos alunos e de um observador externo (também através de diários), além de usarmos gravações em âudio durante as aulas. Os dados coletados pelos diários e gravações não serão aqui analisados em termos de quantificação, pois nāo se trata de medir, controlar ou procurar as possiveis causas que levam a determinadas "conseqüências", mas de descrever uma situação dentro de um contexto, de aguçar a percepção sobre uma situação que já está ocorrendo. Como lembra Van Lier, uma abordagem causal é inadequada na pesquisa em sala de aula, pois "teaching does not cause learning" (1989, p. 38). Van Lier recorda que Humboldt já havia afirmado que nāo é possivel ensinar uma lingua, mas sim criar condiçōes para que o processo de ensino se viabilize.

No caso do ensino da tradução, a ênfase encontra-se na conscientizaçāo do que implica ser um tradutor e no desenvolvimento de uma percepção crítica em relação à tarefa. $O$ ensino, nas palavras de Feldman, é "a criação de uma nova condição do conhecimento, a criação de uma disposição original para a aprendizagem" (apud Arrojo, 1993, p. 143). 
A presente pesquisa está voltada para o que "ocorre" nas aulas de PT, isto é, para as estratégias que o professor propicia para que o aluno aprenda e para a forma como o aluno responde a estes estimulos. Contudo, gostariamos de enfatizar que o trabalho do professor-etnógrafo de maneira alguma pode ser entendido como definitivo ou conclusivo. Afinal,

A good ethnographer will never claim to have found sufficient or even adequate clues to knowledge about the people studied. Every insight generates further questions, and every question suggests further avenues for exploration. (Lier, 1989, p. 47)

Um aspecto que nos parece particularmente positivo neste tipo de pesquisa é que a investigação realizada pelo professor e pelo aluno estimula em ambos a curiosidade e a criticidade sobre o processo em que estão imersos e a respeito do qual surpreendentemente pouco sabem. Envolvidos na pesquisa, professor e aluno têm a oportunidade de conscientizar-se das necessidades e expectativas que trazem para a sala de aula e da forma como as relaçōes intersubjetivas atuam sobre o processo de ensinaraprender. A sala de aula torna-se um texto a ser lido, isto é, a ser produzido, fato que renova a percepçāo sobre uma situação tão conhecida quanto inquestionada. Segundo Erickson, ao adotar a mesma estratégia do filósofo, o etnógrafo torna o familiar estranho:

The ethnographer must adopt the critical stance of the philosopher, continually questioning the grounds of the conventional, examining the obvious, that is so taken-for-granted by cultural insiders that it becomes invisible to them. Often it is the taken-for-granted aspects of an institution that in the final analysis turn out to be the most significant. (1984, p. 62)

Vista sob nova ótica, a experiência de estar em sala de aula torna-se mais rica quando sua complexidade passa a ser reconhecida.

Outro aspecto crucial a ser levado em consideração quando se procura realizar uma pesquisa etnográfica é o método que 
se adota, pois ele irá, em grande medida, determinar as descobertas, "moldar" (dar forma a) a própria investigação. Em nosso estudo, optamos pelo "método naturalista" ("naturalistic enquiry"), que se define como aquele em que o pesquisador não tenta intervir no contexto da pesquisa e não procura controlar o desenrolar "natural" dos eventos (Allwright, 1991, p. 40-2), embora-é preciso ressaltar -, os próprios instrumentos de observação representem uma forma de intervenção na sala de aula. Esse método se adequa aos nossos objetivos, porque nossa intenção não é controlar variáveis, mas descrever e examinar de que forma os padrōes de interação, que ocorrem nas aulas de PT, contribuem para o desenvolvimento profissional dos tradutores que pretendemos formar. Nossa prioridade nāo é tecer generalizaçōes, e sim, com base na experiência de ensino na PUC-SP, oferecer material de reflexão que seja válido para outros contextos especificos.

Além disso, trabalhar com informações obtidas por meio de diários e gravaçōes implica a questão da análise destes dados. Uma vez que partilhamos do pressuposto de que nenhuma leitura pode ser independente do sujeito que a produz, optamos por utilizar a análise que Allwright define como "qualitativa", ou interpretativa:

Qualitative data, such as a set of diaries kept by learners, would typically be considered subjective, a record of opinions and perceptions, rather than (or in addition to) 'facts'. For some researchers, learner's diaries are of interest not because they hold the 'truth' about something, but precisely because they are a record of opinions and perceptions important to the learners - ideas which cannot easily be tapped in other ways. (1991, p. 67)

A triangulação dos dados tem por objetivo a inclusāo de perspectivas múltiplas; contudo, os dados coletados serão interpretados pelo pesquisador, que no caso é também o professor. Por esse motivo, este último deve procurar ser especialmente critico a respeito de sua própria leitura. 


\section{Definindo o contexto}

As aulas de Prática de Tradução (PT) da PUC-SP, que os graduandos são orientados a cursar a partir do $5^{\circ}$ semestre serão o foco de nossa pesquisa. Os 26-40 créditos (número minimo e máximo) de PT podem ser cumpridos em módulos de 2,4 ou 6 créditos. Neste estudo, selecionamos observar oito aulas de PT (correspondentes a quatro dias de aula de dois créditos/dia), por nós ministradas em maio de 1996, em um grupo de 20 alunas entre 19 e 30 anos, cuja experiência com tradução era bastante variável: algumas nunca haviam traduzido um texto, outras haviam cursado anteriormente créditos de PT, enquanto outras jâ estavam trabalhando profissionalmente com tradução.

A disciplina Prática de Traduçāo tem por objetivo preparar o aluno para a utilização adequada das estratégias envolvidas no processo de tradução; possibilitar a análise e reflexão sobre o processo tradutório; tornar o aluno capaz de estabelecer relações de comparação entre linguas e culturas; promover a reflexão sobre a funçāo social, funcional e ética do tradutor. A metodologia estipulada pelo professor para alcançar os objetivos e avaliar as atividades desenvolvidas pelos alunos constitui-se na discussão das traduções em grupos de 2 a 3 integrantes, e duas traduçōes individuais feitas em sala de aula, com consulta.

O trabalho em pequenos grupos tem sido adotado nas aulas de PT por acreditarmos que sua eficiência é muito superior à da metodologia tradicionalmente utilizada nestas aulas (inclusive por nós mesmos) que consiste na apresentação das versōes individuais ao conjunto de colegas e ao professor, o qual julga e avalia cada uma das propostas. Nossa insatisfação com a dinâmica tradicional centrada na figura do professor baseia-se em diversas constataçōes que fomos tecendo ao longo de nossa prática didática e encontra respaldo nas observaçōes feitas por Frota e Martins, do Departamento de Letras da PUC-RJ, em ensaio dedicado à reflexão do sistema avaliativo nas aulas de Prática de Tradução:

A dinâmica tradicionalmente usada nas aulas de traduçāo é a da prática de tradução comentada, onde se comparam as solu-

TRADTERM, 4(2), $2^{\circ}$ semestre de 1997, p. $97-128$ 
çöes dos aprendizes em textos por eles previamente traduzidos. As discussōes são conduzidas pelo professor, que fornece o modelo para a avaliação das diversas soluçōes apresentadas. Nesse tipo de abordagem, que privilegia o produto final da tradução e não o processo tradutório, não há oportunidade para que os aprendizes justifiquem suas escolhas quando estas não coincidem com aquelas consideradas 'boas' ou 'certas' pelo professor, que desempenha o papel de juiz. (s/d)

Insatisfeitos com a dinâmica de "grupão", passamos a adotar a discussão em grupos pequenos, e nossa experiência nesse sentido tem sido bastante positiva. Em primeiro lugar, ao centralizar a tarefa na mão de grupos de alunos, o professor deslocase de seu lugar tradicional à frente da classe, estimulando a formação de vários núcleos que passam a ter poder de decisão sobre o que é "correto" em cada caso tradutório. Nos grupos, os "tradutandos" podem consultar-se sobre dúvidas que tenham, propor novas alternativas e debater sobre as possiveis soluções encontradas, utilizando-se das mais diversas fontes de pesquisa para justificar suas escolhas. Nesse contexto, o professor é responsável pelo encaminhamento de soluções, e sua função é provocar questöes sobre o entendimento do texto, solicitar esclarecimentos em determinadas opções, exigir a explicitação dos critérios tradutórios utilizados e indicar materiais de referência ou textos auxiliares. Gostariamos de deixar claro que o professor continua ser a instância de poder e autoridade; no entanto, em vez de ter que oferecer respostas "prontas" - que parecem revesti-lo de uma aura mágica de sabedoria -, ele passa a usufruir do espaço e do tempo que lhe reservam os grupos para apontar caminhos e atalhos, inclusive os que ele mesmo utilizou, e que podem conduzir os alunos às suas próprias conclusões.

O papel do professor de tradução é, no nosso entendimento, orientar os grupos sempre que houver um "impasse" ou uma "crise" - situaçōes que caberá a cada grupo identificar. O professor deve incitar os alunos a desenvolverem argumentos e exercitarem sua capacidade critica e criativa sem, contudo, deixar de julgar as traduçōes dos alunos e expor suas próprias opçōes tradutórias. $O$ poder e a autoridade do professor provêm de sua 
competência em julgar as vảrias sugestōes e estimular um debate em que argumentos e explicaçōes conduzam às soluções mais apropriadas, mesmo que isto implique ao professor reavaliar sua própria proposta inicial.

Alèm de redimensionar o papel do professor nas aulas de PT, a opção pelo trabalho em grupos nos parece ser mais proficua e estimulante em vários outros sentidos. Freqüentemente, nas aulas tradicionais, quando o aluno solicitado a ler sua tradução não fornece uma versão satisfatória, o professor ou algum aluno mais pesquisador ou mais experiente divulgam suas traduções, que sāo acatadas pela sala sem maior questionamento. Jâ nos grupinhos, todos os alunos têm a oportunidade de expor suas traduções, discuti-las e, caso não encontrem uma alternativa adequada, encarregar-se de realizar tal pesquisa para a aula seguinte, fortalecendo, desta maneira, o espirito investigativo que toda traduçāo requer.

Também no tocante à etapa de revisão, tão essencial para a elaboração "final" do texto, o tradicional esquema professoralunos prejudica consideravelmente a tarefa; como nesse caso a unidade para discussāo é a frase, e várias possibilidades são aceitâveis, fica dificil, ou até impossivel, reler um texto e adequálo em termos de registro, sintaxe e coesão. Já nos grupinhos, em uma aula destinada a este fim, o texto é revisto com maior detalhe e empenho, as escolhas são feitas tendo em vista o conjunto do tecido discursivo, e a traduçāo resultante revela-se de melhor qualidade e mais coerente.

Evidentemente, seria ingenuidade argumentar que a metodologia que defendemos está isenta de problemas. Trabalhar em grupos pressupõe responsabilidade e comprometimento com uma determinada proposta, iniciativa, espirito de pesquisa e cooperação, atributos com os quais nem sempre se pode contar. Às vezes, o nivel de motivação ou engajamento em relaçāo à disciplina ou ao curso difere consideravelmente entre os membros, prejudicando, ou até mesmo, inviabilizando as atividades. Por este motivo, os grupos são organizados pelos alunos sob orientação do professor, que procura conciliar o nivel de experiência em traduçāo com as afinidades pessoais/acadêmicas dos futu- 
ros tradutores. ${ }^{2} \mathrm{O}$ momento de formação dos grupos é, portanto, essencial para o desenvolvimento posterior das atividades em aula, e, por esta razāo, sāo discutidas nas primeiras aulas as vantagens e desvantagens desse método de trabalho, contrapondo-o ao método tradicional das aulas de tradução, para que se possa ter clareza sobre a estratégia a adotar.

Outro aspecto que é preciso levar em conta é que a avaliação (nota) obtida nos textos traduzidos em grupos tende a ocultar diferenças quanto aos desempenhos individuais. Porém, o alvo do professor não é propriamente o produto final, mas o processo de confecção das traduçōes. As provas individuais constituem um outro tipo de exercicio tradutório e fornecem dados para a apreciação do trabalho de cada estudante.

Para chegar à análise, e concluir esta seçāo, gostariamos de ressaltar que temos consciência de que nossa metodologia, bem como tudo que fazemos em sala de aula, tem o contorno de nossos limites e das verdades nas quais (temporariamente) cremos. Isto quer dizer que assumimos o que Snyders chamou "risco pedagógico":

O risco pedagógico, o risco de se induzir os alunos em erro ou de lhes influenciar arbitrariamente a vontade, a fim de os dirigir para os que julgamos ser verdadeiro, esse risco é a própria definiçăo de ensino. (1978, p. 306)

Pesquisadores, professores, alunos e tradutores nāo podem escapar à condição humana da falibilidade. Mais um motivo que nos incita a examinar de que forma o discurso do planejamento e da metodologia "ideal" se concretizam efetivamente na sala de aula.

\section{Em busca de uma percepção critica do processo}

Conforme assinalamos anteriormente, o cruzamento dos dados coletados se, por um lado, não pode garantir uma avalia-

(2) Algumas vezes, alunos de diferentes niveis de experiência com traduçāo têm trabalhado juntos com muito bons resultados. 
ção exata ou precisa da situação observada; por outro, pode propiciar um enriquecimento de perspectivas, uma possibilidade de estabelecer um ponto de vista multissubjetivo, ainda que a análise dos vários registros seja, como no nosso caso, empreendida pelo professor-pesquisador. Para obter um relato dos alunos, solicitamos que anotassem suas experiências na forma de diários escritos nos dias 6, 8, 13 e 15 de maio de 1996. Também pedimos a um grupo de alunos que gravassem em áudio estas aulas, à professora que redigisse diários, e a um observador externo que produzisse um diário das aulas de 8 e 15 de maio. Não lhes foi dada nenhuma orientaçāo sobre o que observar, sendo os observadores livres para registrar suas vivências. $O$ texto em discussão/traduçāo neste periodo intitulava-se "Shards of Speech" (The Sciences de jan./fev. de 1996, p. 34-5).

A partir da leitura dos diários foi possivel detectar a existência de uma clara distinção de pontos de vista sobre as atividades, a qual coincide com o nivel de experiência dos alunos: dois grupos (4 e 5) já estavam cursando o $3^{\circ}$ semestre de PT, enquanto os outros três grupos $(1,2$ e 3$)$ estavam no $1^{\circ}$ semestre desta disciplina (entre eles, somente uma aluna já havia cursado um semestre). Assim, os relatórios dos alunos "iniciantes" revelaram que o texto a ser traduzido foi considerado muito dificil, e que esta dificuldade não diminuiu ao longo da discussāo.

Os problemas e obstáculos sentidos por esses grupos foram esclarecidos recorrendo-se à professora, que, nas quatro aulas, foi chamada para "resolver" questões de compreensão, de diversidade de interpretaçōes e de lingua inglesa e portuguesa. Vejamos o seguinte relato, feito pelo grupo 2:

Achamos a aula hoje mais 'pesada', pois quando cada elemento do grupo falava o texto traduzido de casa, nós percebiamos que cada um de nós tínhamos diferentes interpretaçōes e com isso não chegávamos a um entendimento final. Entāo, chamamos a professora para que ela pudesse nos esclarecer o trecho onde houve dúvida. Com isso, chegamos a uma conclusão final. $(08 / 05 / 96)$

Neste caso, como em outros momentos, a intervençāo da professora parece ter sido "providencial", pois funcionou como 
"saida" para um impasse. Embora desde as primeiras aulas a professora tivesse enfatizado que sua função era orientar o trabalho, a solicitação de esclarecimento, na expectativa de uma solução, corrobora a idéia de que o aluno tende a aceitar a palavra do professor como algo inquestionável e definitivo. Sem dúvida, este é, para nós, um aspecto crucial do processo de ensinoaprendizagem da tradução: por um lado, o professor efetivamente tem o papel de orientador e está preparado para encaminhar dúvidas e apontar soluçōes; por outro, nāo se trata de atribuir a ele a responsabilidade pelas opções, ou de pressupor que é dele a última palavra, a interpretaçāo "correta", única e insuspeita. Para que o aluno se assuma como co-autor do texto que traduz é essencial que se perceba responsável por seu aprendizado e que acredite que é capaz de propor alternativas (até melhores que as do professor) - atitude dificil para muitos, dado o papel submisso que vêm exercendo ao longo de sua escolaridade.

Outro aspecto ligado ao papel do tradutor como produtor de um texto refere-se ao uso de dicionários mono ou bilingües: "Para solucionar estes problemas, consultamos a professora e também os dicionários que trouxemos de casa" (grupo 2, 06/05/96).

Acreditamos que a consulta aos materiais de referência é um dado bastante importante tendo em vista que reflete o espirito de pesquisa e a disposição para solucionar problemas, atributos cruciais para a realizaçāo da tarefa tradutória. As possiveis dificuldades dos alunos quanto ao manuseio das obras de referência podem ser partilhadas e resolvidas nos vários encontros.

O fato de o trabalho estar se desenvolvendo de forma lenta tambèm foi mencionado nos diários. Isto parece ter preocupado alguns alunos, mesmo após a professora ter alertado sobre a complexidade do texto em traduçāo: "Estamos tendo dificuldade para passar para o português o que entendemos do texto.(...) Estamos traduzindo um parágrafo por aula" (grupo 2, 13/05/96).

O grupo 1 parece ter compreendido melhor a necessidade de ter que despender mais tempo do que o esperado: "Apesar de estarmos trabalhando lentamente, pois o texto requer muita paciência, conseguimos ver progressos" (08/05/96). 
A percepção de que o processo de tradução requer tempo, e freqüentemente persistência, é problemática para os alunos porque muitos parecem partilhar da crença de que traduzir è uma atividade relativamente simples, que pressupōe tão somente o conhecimento do vocabulário da lingua estrangeira e de alguns hábitos de outro povo. Esta visão de tradução é corroborada pelas palavras de alguns tradutores, como, por exemplo, Geir Campos:

... traduzir nada mais é do que isto: fazer passar, de uma lingua para outra, um texto escrito na primeira delas (...) o que o tradutor faz é apenas isto. (1986, p.7-8)

Principalmente em relação aos alunos que estāo cursando PT pela primeira vez, temos observado, ao longo dos semestres (ver também pesquisa CEPE/95), que alguns estereótipos ligados à tradução são bastante recorrentes, entre eles a idéia de que traduzir é um ato simples que só envolve ler numa lingua e escrever em outra, uma tarefa, portanto, rápida e pouco complexa, o que explica uma certa frustração e até um certo sofrimento quando o processo se revela dispendioso ou laborioso. (Ler e escrever também são processos a respeito dos quais os alunos são muito pouco conscientes.)

Quanto aos grupos "mais experientes" (grupos 4 e 5, que já haviam cursado entre 12 e 14 créditos), constatamos uma menor menção de consulta à professora para resolução de seus problemas. Por exemplo, embora no diário do dia 06/05, o grupo 4 tenha registrado seis dúvidas que ocorreram durante a discussão, na aula seguinte, os alunos as solucionaram $\dot{e}$ registraram a consulta a outras fontes para resolver as dificuldades que permaneceram: "Chegamos à conclusão de que precisamos recorrer a outras fontes (para certas dúvidas)".

$\mathrm{Na}$ aula do dia 15/05, as alunas mostraram que as dificuldades foram solucionadas através de pesquisa: "A Carol fez algumas pesquisas que faltavam em enciclopédias, sobre o caxemira (não sabiamos se era caxemira ou cachemira e descobrimos que pode ser tanto um como outro) e sobre outras dúvidas mais".

Também o grupo 5 explicitou em seu diário do dia 13/05 a consulta a materiais que pudessem esclarecer suas dúvidas: 
"Então resolvemos ir à hemeroteca tirar algumas dúvidas como: 1- Data de mudança de Calcutá de colônia para sede do governo britânico; 2-O termo the Vedas' ou the Rig Vedas'; 3- sobre Willian Jones".

Observa-se uma maior iniciativa e autonomia desses alunos em termos de procurar esclarecer dúvidas e de buscar informação por seus próprios meios. A professora não foi consultada para fornecer dados que podem ser obtidos via consulta a dicionários ou livros, mas para orientar sobre procedimentos tradutórios, como podemos observar a seguir: "Discutimos também sobre a possibilidade de corrigir a data errada do texto original com a professora. Ela disse que quando é um dado histórico, deve-se corrigir. Quando forem conceitos errados ou opiniāo pessoal do autor, nāo podemos interferir" (15/05/96).

A expectativa em relaçāo ao papel do professor de traduçāo está ligada à visão que estes alunos têm do que implica o ato de traduzir. Provavelmente por terem mais experiência com tradução e por estarem mais familiarizados com a dinâmica da discussão em grupos pequenos, os grupos 4 e 5 terminaram o trabalho primeiro, e consultaram a professora menos vezes.

Passemos agora aos diários da professora sobre estas aulas, procurando resgatar os aspectos mencionados e outros que sejam interessantes comentar.

Em primeiro lugar, a distinção entre grupos iniciantes e experientes (como definido acima) fica clara nos relatos da professora, que anota (visualiza) dois tipos de procedimentos de trabalho e de atitudes que praticamente se contrapõem:

Os alunos mais experientes trazem as traduçōes, discutem, deixam as dúvidas para serem perguntadas depois. Os alunos 'novos' ficam 'empacados' nas dúvidas até eu chegar para 'responder' e têm a expectativa de que eu dê respostas; parecem não perceber o processo, não valorizá-lo, têm pressa, acho que ficam inseguros em relaçāo ao tempo (se vai dar para traduzir). $(08 / 05 / 96)$

Parece realmente haver uma correlação entre (pelo menos) duas atitudes diante do que é traduzir e o estágio curricular 
em que se encontram os futuros tradutores. De fato, em vários diários e sob diversas perspectivas, esta divisão insiste, levando-nos à (feliz) suposiçāo de que, neste grupo específico de PT, os alunos mais adiantados tenham mudado, ao longo do curso, sua visão a respeito do que é o trabalho do tradutor, tornando-se, portanto, mais preparados para o conjunto de decisōes que a tarefa tradutória requer.

Nos relatos feitos, lê-se também uma inquietação quanto ao andamento dos trabalhos, uma dúvida mesmo quanto à eficiência da dinâmica de grupo: "Nos grupos onde alguém faltou, o trabalho não flui muito bem e isto é um problema deste tipo de aula. Preciso falar sobre isso com as alunas; nos grupos onde uma nāo fez a tradução ou fez mal feito, a discussāo é mais pobre, mixa" (13/05/96).

Note-se que a professora parece suspeitar de sua própria metodologia, desconfiando de seus próprios critérios em relação à orientação que é solicitada a dar aos alunos. Isto talvez se deva à consciência que a pesquisa estimula no observador, ao questionamento agudo a que foi levada a professora no intuito de gravar todas as suas impressōes, sem se poupar:

"Alguns alunos ficam esperando a resposta pronta. Não vejo em mim uma clareza sobre os critérios que eu uso para "dar respostas" ou nāo. Acho que há um critério mas não está claro para mim, são muitas variáveis: alunas experientes/iniciantes; tipo de dúvida; em geral, eu pergunto a traduçāo delas, o que acharam, do que o texto está falando, o que 'diz' o dicionário, porque o 'autor' estaria dizendo aquilo. Mas, às vezes, dou a minha tradução, não sei bem porquê. Acho que é quando eu não sei como encaminhar mais para que cheguem sozinhas." $(15 / 05 / 96)$

Percebemos uma auto-avaliação rigorosa, um questionamento intenso, provavelmente (exa)gerado pelo estado de alerta em que se encontra a professora ao examinar sua prática de forma critica e explicita. O próprio papel do professor parece estar em jogo, na medida que a professora reconhece que alguns de seus critérios para encaminhar as dúvidas expostas pelos 
grupos não estão claros. Tendo em vista que os alunos iniciantes atribuem ao professor a função tradicional de "responsável pela solução de problemas", esta indefiniçāo da professora em relação à sua conduta como orientadora pode estar dificultando a adoção de uma nova postura dos estudantes diante de seu processo de aprendizagem, aspecto que a professora tanto parece valorizar. Contudo, é possivel que a proposta de se deter sobre sua prática didática tenha suscitado na professora uma autocritica acentuada. Sua atividade rotineira passou a ficar sob suspeita, adquirindo novas nuanças porque se tornou objeto de cuidadosa atenção: "Alguns grupos me solicitam, outros esperam que eu 'passe'. Preciso ficar alerta o tempo todo" (15/05/96).

Conforme vamos procedendo à análise dos relatos e refletindo sobre os vários ângulos iluminados, vai ficando cada vez mais em evidência que pesquisador e professor, observador e observado, vão tecendo um diâlogo que ao mesmo tempo os contrapōe e os aproxima.

Vejamos agora de que forma os diários produzidos pela observadora externa, prof ${ }^{a}$. Walkyria Montemór, também da PUC$\mathrm{SP}$, enriquecem nossa percepção do processo de ensino-aprendizagem da tradução. As anotaçōes feitas referem-se às aulas dos dias 8 e 15 de maio, durante as quais a prof ${ }^{a}$. Walkyria, conhecida pela maior parte dos alunos, foi acompanhando por algum tempo os trabalhos de cada grupo, sem ter conhecimento de quais estudantes haviam ou não cursado a disciplina anteriormente.

Como ocorreu com os registros analisados, o andamento das discussōes, bem como os procedimentos empregados nos diferentes grupos, foi bastante divergente, confirmando a existência de dois 'blocos': um, mais disposto a investigar e resolver seus próprios dilemas e, portanto, mais independente da figura do professor, e outro que carecia de informaçōes e de método para obtê-las, como podemos ver a seguir:

Alunas haviam feito a tradução do texto em casa. Em aula compararam as soluçōes que cada uma havia dado. Houve pesquisa em casa sobre termos. Uma delas trouxe um livro já traduzido contendo informações culturais que elucidavam a dúvida levantada. Quando a professora passou pelo grupo, houve 
perguntas das alunas sobre dúvidas. A professora sugeriu esclarecer uma delas em fonte mais fidedigna: professores de Lingūistica, uma vez que se tratava de uma terminologia especifica da área em questão. (15/05/96)

Não haviam entendido o texto que traduziram. Não tinham conhecimento sobre o fato de haver uma tentativa dos franceses de banir as influências lingüisticas estrangeiras. Por esta razão, não concluiam sobre o melhor termo. Procuraram em um dicionário o qual pegaram com o grupo vizinho e encontraram uma palavra que talvez pudesse ser utilizada: usurpar; contudo, não sabiam o significado dela em português. (08/05/96)

Tendo observado as atividades dos grupos, a prof ${ }^{\text {a }}$. Walkyria concluiu (ou intuiu) que as dificuldades apresentadas por alguns grupos refletiam sua pouca experiència com traduçāo, e eram encaradas pela professora da disciplina como etapa de um processo:

Este é um grupo mais inexperiente. Haviam feito a traduçāo em casa e estavam comparando seus trabalhos. Contudo, parece que traduziram sem entender o conteúdo do texto. Faltou bagagem cultural. Por exemplo: a trecho falava sobre a evolução do transporte desde o lombo do cavalo ao veiculo com rodas $e$ uma delas entendia que era veiculo com volante. No entanto, parece ser assim mesmo com iniciantes. A troca de informaçōes é benéfica para eles, cultural e lingüisticamente falando. (15/05/96 - grifos nossos)

Conforme comentamos anteriormente, segundo nossa experiência como professores de PT, e com base em estudo anterior (CEPE, 1995), os alunos que estão iniciando o trajeto têm uma concepção bastante estereotipada do que é tradução, calcada nas idéias a nosso ver equivocadas, nāo só de leigos no assunto, mas também de tradutores e estudiosos do fenômeno tradutório. Porque ignoram que são produtores de sentido e de textos, estes estudantes se surpreendem com a responsabilidade que a elaboração de uma tradução implica e - queremos crer -, através das discussões em grupo, vão gradualmente tomando consciência do processo. 


\section{Novos dados entram em jogo}

Aos pontos de vista analisados, falta-nos acrescentar o exame das gravações em áudio das discussōes empreendidas por um grupo de três alunas durante três das quatro aulas selecionadas (um problema com o gravador inviabilizou a gravaçāo da aula do dia 08/05). Este grupo se constituia por graduandas que cursavam seu primeiro semestre de Prática de Tradução. A escolha de observar este grupo foi feita com base na expectativa de captar a dinâmica de trabalho dos alunos iniciantes no que diz respeito a seus pressupostos e atitudes diante da tarefa de traduzir textos, à relação entre os membros do grupo em termos de responsabilidade, cooperação, iniciativa e interação, e a seu relacionamento com a professora.

De todos os registros até o momento analisados, a gravação $\mathrm{cm}$ áudio nos pareceu o mais rico quanto à percepção de uma séric de questões muito pertinentes para nosso estudo. Primeiramente, é possivel constatar que, apesar de sua experiência limitada com tradução - este era o quinto texto que traduziam -, muitos dos comentários das alunas refletem o conhecimento de algumas estratégias de tradução, como por exemplo, logo no inicio da discussāo, no dia 06/05, a proposta de traduzir o titulo/subtitulo após o texto ter sido longamente discutido, tendo em mente o público brasileiro ao qual se destinaria a traduçāo. Contudo, as gravaçōes revelam também muitos preconceitos $\mathrm{e}$ desconhecimento em relação ao processo de traduçāo.

A leitura das discussões gravadas aponta para uma certa dificuldade em trabalhar e produzir em grupo. Parece haver uma falta de familiaridade com o processo de avaliar a fala das colegas e de ser por elas avaliada. Às vezes, após a exposiçāo das várias traduçōes, segue-se um "desencontro" que dura muitos minutos: a sensaçāo que temos é a de que lhes faltam critérios para dar prosseguimento à comparação entre as alternativas e compreender a diferença entre as versões propostas. Outras vezes, os diálogos demoram-se em torno de questōes envolvendo pontuação ou ordem de advérbios. Nestes casos, observamos que não hả uma clareza a respeito da etapa de revisão, cuja função é justamente resolver problemas dessa natureza. (Embora orientaçōes a respeito tenham sido fornecidas.) 
A dificuldade de avançar nas discussōes parece estar relacionada a um tipo de insegurança sobre a qualidade do próprio trabalho. Por exemplo, as três alunas (A, B e C) procuram lidar com a critica umas das outras antecipando possiveis (temidas?) reações a seus textos:

B-Olha só o que eu coloquei, gente: não vão dar risada. "Por um longo ..."

A-Não. Ninguém riu da minha também.

$B$ - "Por um longo periodo, a França - língua franca da diplomacia - havia sido usurpada pelos ingleses..."

A-O que é "usurpada"?

$C$ - Eu também coloquei isso..

$B-{ }^{\alpha}$ Foi usurpada pelos ingleses neste século, foi forçada a colocar com este vencedor" ... O que é isso?

C-(rindo) A minha tá toda pulada, o: "este longo" eu pulei, porque pensei que podia ser de "longo tempo", "durante anos", "por séculos", estas coisas.

Chama-nos a atenção que as alunas pareçam mais preocupadas em justificar seus erros do que defender suas opções. $O$ medo de se equivocar e de se expor ao julgamento das colegas vem acompanhado das mais insólitas explicações:.

$B-E u$ acho que é "experiente".

$C-E$ se colocar "completo"?

$B-$ "Lingüista completo"?

C-Porque eu acho que esse daqui, é aquela linguagem de totalidade mesmo, de ser o máximo.

A-Mas ai vai ficar estranho.

$B$ - "Experiente." Você não fala que a pessoa é "completa", você fala que é "experiente".

A-Até parece que tem um lingüista incompleto.

$\mathrm{C}-E u$ acho que é frase de linguagem de mundo, isso, né? $\mathrm{Na}$ minha linguagem de mundo é assim: você ser experiente pode ser experiente em venda de sapato, mas você não bate uma régua porque eu sou melhor ainda que você. Você entendeu? (06/05/96) (grifos nossos) 
É complicado para as futuras tradutoras negociar a palavra, ponderar diante das opçōes e em especial defender uma colocaçāo. Isso pode ser resultado, por um lado, da falta de prática de conduzir o próprio aprendizado: afinal, avaliar e decidir sobre o que é melhor é atribuição do professor, ao aluno cabe cumprir a tarefa; por outro lado, não há ainda uma clareza sobre o papel do tradutor e do processo de traduzir. A falta de convicção com que lêem suas traduçōes - como algo que escreveram, mas pelo qual não se responsabilizam - parece decorrer de uma incompreensão sobre como devem atuar: se o sentido está no texto de partida, então basta passá-lo para outro idioma. Entretanto, esta tese é incansavelmente desafiada a cada sentença. Vejamos um exemplo. Após uma longa discussão sobre uma frase - interrompida, aliás, por conversa paralela sobre a venda de um computador (interrupção vista por nós como "fuga" ou "descanso") - as alunas chegam à conclusão de que criaram problemas à toa ("viajamos de bobeira"). Em seguida, uma vez estabelecida uma traduçāo satisfatória, vejamos o que as alunas $\mathrm{C}$ e D declaram:

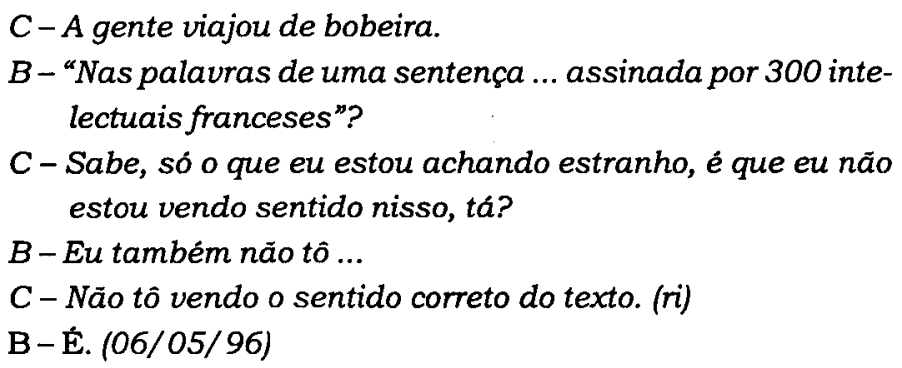

É curioso que a aluna $\mathrm{C}$ ri quando decide abrir o jogo $\mathrm{e}$ sente confirmação por parte da colega. É como se ela tivesse, enfim, revelado algo que se esforçara por ocultar: o fato de que a mera reescritura de uma sentença em outro idioma não é linguagem e que, para dar vida a um texto, é preciso produzir sentido. Mais adiante, ao final da discussão, observa-se um avanço nesta direçāo, quando as futuras tradutoras conversam sobre o texto, na busca por construir um sentido:

B-Mas "as indústrias automobilísticas substituem"?

TradTERm, 4(2), $2^{\circ}$ semestre de 1997 , p. 97-128 
C-Por que? As indústrias automobilísticas nāo iam entrar na lei de 94.

A-Por isso elas têm que substituir, por causa da lei. (13/05/ 96)

A indiscutivel relevância de uma percepção critica sobre o ato tradutório e da consolidação dessa percepção vem acompanhada pela adoção de uma série de atitudes não menos importantes para a conscientizaçāo da tarefa do tradutor. Exemplo disso é a criação do hábito de acatar intervençōes e de valorizar a contribuição que o outro pode dar para a melhoria da qualidade do texto em tradução. A "cobrança" de uma pesquisa séria ("Você nem procurou no dicionário, né?") e o intercâmbio de informaçōes sobre materiais de pesquisa são essenciais para despertar a iniciativa e a responsabilidade pela confecção textual:

C-Eu traduzi até o final, só que muita coisa ficou pendente, porque eu estava sem o dicionário cultural.

A - Mas eu só peguei o dicionário cultural pra isso aqui, ó, o resto foi tudo sem e näo tive problema nenhum.

$C-E u$ tive, porque meu dicionário é desse pequeno, muitas coisas não tinha, palavras, algumas palavras eu nāo achei...Tem linguas que no meu dicionário não têm traduçāo.

A-E, mas no dicionário do Webster tem todas.

C-Então, eu nảo tenho em casa.

B - Vai, vamos começar. (15/05/96)

É a colega que "cobra" a pesquisa, e não a professora; ora, se a colega "encontrou" as respostas, isso prova que o trabalho pode ser bem feito se houver uma pesquisa adequada. Entretanto, surpreendeu-nos a dificuldade às vezes apresentada na utilizaçāo do dicionário, principalmente tendo em vista que disciplinas do primeiro ano estão incumbidas de preparar os alunos para esta atividade tão vital ao estudante de Letras.

No exame das gravações, encontramos confirmação de que a dinâmica de trocas em grupo promove o desenvolvimento de um atributo que nesta etapa parece ainda se encontrar em es- 
tágio embrionário: a autocritica. Ao ler sua versão para os colegas, a tradutanda tem a oportunidade de distanciar-se de seu texto e revê-lo criticamente, como se pode constatar no seguinte diălogo:

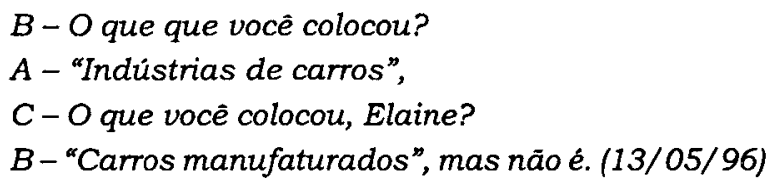

Acreditamos que este continuo ouvir o outro e se ouvir contribuirá para o aprimoramento da tão fundamental autocritica do tradutor. Além disso, a discussão das traduções em grupo propicia uma série de reflexões sobre o processo de traduzir, que emergiram também nos relatos escritos analisados anteriormente. Há, por exemplo, vários comentários sobre o nivel de dificuldade do texto e o tempo requerido para traduzi-lo:

$A-E u$ acho este texto chato. (riem)

$C-E$, tá difícil, né, não é que tá... é que tá muito... complicadinho.

$B$-Nós temos que procurar tudo.

C-É um texto que parece fácil mas que tá muito ... tá uma linguagem acho que muito formal.

A - Não. Aqui até o final do parágrafo é legal.

$C-E$ depois? Eu vim só até aqui embaixo. Esse lado aqui eu não cheguei. Você já traduziu aqui?

$B-$ Ahhh é grande.

$C-$ Enorme.

$B$-A gente vai levar um ano pra fazer isso daqui.

C-Leila!

$B-A$ gente nem o primeiro parágrafo terminou ... (06/05/96)

A expectativa dos alunos iniciantes parece ser a de que traduzir é uma tarefa simples, que, portanto, deveria consumir pouco tempo. Lidar com a complexidade de interpretar e fabricar textos provoca certa frustraçāo, a qual pode ser detectada em vários momentos das aulas gravadas. ("Você fica meia hora e 
não rende, nê? Você fica meia hora num negocinho." Ou: "A gente tá perdendo um tempão com esta palavra".)

Já que consiste de uma tarefa relativamente simples, as futuras tradutoras muitas vezes procuram justificar uma traduçāo malfeita responsabilizando as condições de realização do trabalho:

B-Eu coloquei assim: “ambas originadas dos verbos, em forma de gramática". Viajei!

(risos)

B - Nossa, você lê assim, eu traduzi no trem. De baldeação, ainda.

C-Sabe o que eu acho? Sinceramente? Eu acho que a gente que fica traduzindo assim no trem, tipo assim, fim de semana eu pego pra traduzir, eu começo a traduzir certinho, só que começa me dar muito sono.

$B-E$ que eu não tenho tempo mesmo.

C - Eu também não tenho, ai o tempo que eu tenho eu vou traduzindo, só pra não dizer assim, ó ela não fez. Então eu faço. Chega aqui, eu começo a polir. (13/05/96)

Por um lado, os alunos sentem-se constrangidos por terem realizado uma traduçāo insatisfatória e atribuem o fato à falta de tempo; por outro, este constrangimento nāo os impele a resolver o problema do tempo, estimulando até a defesa de um falso método: fazer um rascunho precário é uma estratégia planejada pois durante a aula é que a tradução deve ser "polida". Novamente aqui, o que está em jogo é uma visão equivocada do que é traduzir, e uma incompreensāo da natureza da atividade que a professora solicita aos alunos. Evidentemente, traduçōes feitas às pressas requerem muito mais tempo de discussão, dificultando ainda mais o andamento do trabalho.

A transcrição acima mostra que, nas discussōes em grupo, as futuras tradutoras trocam informações sobre os procedimentos tradutórios que adotam. A aluna $\mathrm{C}$, que acredita que a tradução deve ser feita só por fazer, para nāo deixar em branco, defende a dita tradução literal como um primeiro passo, que será depois aprimorado. Contudo, as colegas, nas duas passagens abaixo, discordam deste procedimento: 
$B$ - "Yet bearing to both of them a strong affinity."

$C-E$ ainda assim, coloquei bem literal pra tentar arrumar.

A-Mas ai fica pior...

C- "Ainda ruma para ambas delas uma forte afinidade."

A-Bem literal fica pior eu acho.

C-Não, não, bem literal pra poder polir, porque se você ler com a frase de cima, esta daqui tem sentido só que ela tá ... desestruturada. Era só colocar uma (ininteligivel)... (13/05/96)

Ou:

C-Mas aqui năo diz que ele achou todas. Quer dizer ele tem achado, né? As pistas achadas.

A - Esta frase não tem jeito de traduzir ao pé da letra, né?

$B-N a ̃ o$. Você tem que interpretar ela e colocar. (15/05/96)

A nosso ver, esta troca de experiências e estratégias é um meio eficaz de pôr em cheque determinadas concepçōes, trazendo para a prática questões que tradicionalmente são abordadas apenas nas aulas de Teoria da Tradução. O exercício tradutório fornece um material riquissimo para reflexão, ao dar ao aluno a oportunidade de verificar suas idêias, confrontando-as àquilo que ele efetivamente faz. Em outro momento, a tradutanda $\mathrm{C}$ explicita sua crença no "sentido", como aquilo que deve permanecer na tradução, ao mesmo tempo que defende o conceito de sinonimia:

$C-E$, eu achei como 'origem' tamberm, 'fonte, origem', 'the ...' (lê em inglês). Não sei porque eu deixei 'origem'. Se é a mesma coisa deixa 'fonte'. É sinônimo.

$A-$ Mas tá certo?

$C$ - Ah, é sinônimo. O que não pode é mudar o sentido". (06/05/96)

Entretanto, mais adiante, esta mesma aluna vai provocar um debate em torno da diferença entre "gradativamente" e "pouco a pouco" como traduções para "bit by bit": 
C-Hein? Vamos pensar uma coisinha desse "gradativamente" e "pouco a pouco"? Só prá gente não mudar a idéia, vamos ver se este "pouco a pouco" tá num sentido bem "slow" assim, sabe?

$B-E$, "pouco a pouco".

$C-E$ o "gradativamente", não é uma coisa mais acelerada? Tem que ver isso gente. Será?

$B-N u m$ sei, eu coloquei "pouco a pouco" porque no dicionário estava "bit by bit: pouco a pouco".

$C-E$, "pouco a pouco". Mas eu tô dizendo assim, né, se "pouco a pouco" tem uma idéia mais de "slowly", uma coisa que você vai fazendo não tão rápido. $O$ "gradativamente" é uma coisa mais...

A - Vamos colocar "pouco a pouco", entäo. (06/05/96)

Observe-se aqui que a aluna $C$ não emprega o critério da sinonimia, procurando estabelecer distinções entre palavras que aparentemente têm o "mesmo" sentido. Sua argumentaçāo, porém, nāo é convincente, mas os colegas a acatam sem maior disputa, e a aluna $\mathrm{B}$ se vale do dicionário como autoridade responsâvel pela opção. Embora este tipo de negociaçāo faça parte do jogo, estes alunos nem sempre dominam as regras, ora abrindo mão de suas alternativas sem motivo justificado, ora seguindo o critério de $2 \times 1$, ora ainda recorrendo à professora para "desempatar". A respeito da atuação da professora nas discussōes, é interessante observar como suas colocações são recebidas. Para tal, vejamos o que ocorreu quando da tradução de "hundreds of blunt americanisms":

A-Agora, o que que é isso?

$C-$ "Centenas de blunt". Eu não achei o que é "blunt".

A - Eu não entendi.

$B-O q u e ̂$ ?

C- "Blunt".

$A$ - Quer dizer, eu entendi só que näo consegui traduzir.

C- "blunt", "cego". Ah! Achei mas não... é ....

A-Mas nāo é este sentido.

$B$ - "grosseiros". 
A - "grosseiros" o que?

$C$ - "centenas de ... grosseiros"?

$B-N a ̃ o$ é 'grosseiro', é aquela pessoa selvagem, sabe?

$C$ - "centenas de.. de... americanismos grosseiros... fizeram seus caminhos..." Acho que esta frase, eu tava pensando que seria no sentido assim de... centenas de frases... de palauras, de expressões grosseiras do americano que o francês, sabe? Tipo que nem a gente fala que nem aquele negócio de ... Você tá fazendo Teoria da Tradução, né, que o pessoal fala que tá (ininteligivel), que tá muito cheio....

A - Acho que não é isso. Acho que eles estão falando do... dos... franceses ai, entendeu?

(tempo)

$B-$ "Centenas de grosseiros americanizados"?

A-Hum,.. não faz sentido nenhum.

$C$-Acho que é "centenas de americanismos grosseiros".

A-Ai também não faz ... (rindo)

C-Então aí que está. Prá minha idéia faz. Entendeu ? Aie é que tá ...

A - Tão falando das pessoas, não estão falando das palauras. $C-E$....ai ...

(tempo) (risos.. ininteligivel)

C-Sabe por que que eu estava achando isso? Porque é assim o: "Como os filmes americanos, as cadeias de fast food $e$ os jornais cientificos invadiram a França, centenas de americanismos grosseiros fizeram seus caminhos ...."

A - Não faz sentido, Anita. O que que é "americanismos grosseiros"?

C-Não, assim, eu tô falando de expressōes americanas, isso é americanismo, entendeu, pra mim isso faz sentido. Pra minha cabeça, nâo tô dizendo que tá certo, entendeu? $E$ uma idéia que eu fiz, tanto que eu não escrevi. Eu deixei esse espaço aqui... eu coloquei "centenas de ... fizeram seus caminhos", sei lá. E agora? Chamar a Leila, né?

$A-E$.

C-Leila!

$B-A$ gente nem o primeiro parágrafo terminou ...

$C-O$ que nós fizemos até agora. Nós estamos com dúvida 
neste..."blunt americanisms" a gente num tá conseguindo ...

Leila-Isso. O que é "blunt"?

C - A gente pensou em "grosseiro". Uma coisa grosseira, brusca.

$L-T a ́$ bom.

C-Mas o que seria esses "americanisms"?

$L-$ "Americanismos", mesmo, em português.

C-Entāo, não seriam "americanismos grosseiros"?

$L-I s s o$ !

(risos)

$L-$ Por que vocês não aceitam "americanismos grosseiros"?

$C$ - Não. Porque eu acho que é isso, mas pra elas ...

A-Porque eu não entendi o que é ...

$L-$ Mas vamos continuar a frase, vamos ver como se encaixa.

Ele vai combinar com o que vai vir depois, né?

C-E. Tam tam tam. "centenas de americanismos fizeram seus caminhos dentro de delicadas bocas francesas"...alguma coisa assim ... neste sentido.

L-Isso! Quer dizer ... eles chegaram às delicadas boquinhas francesas.

C-Porque eles são tāo finos, fresquinhos e começaram a falar expressōes americanas, que correspondem aos americanismos grosseiros, não é isso?

$L-\dot{E}, \dot{e}$ isso mesmo.

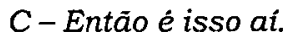

$L$-Falar, por exemplo... aqui ele fala "fast food", aquela coisa americana "fast food". E os franceses falam tudo assim: tururu, aquela boquinha, né? Aquela boquinha toda redondinha, e de repente "fast food", uma coisa

$C$ - grosseira ...

L- uma grosseria para eles. Do ponto de vista das boquinhas delicadas, é uma coisa grosseira.

C - Então é isso ai, né? (13/05/96)

Uma vez que a professora confirma a tradução "americanismos grosseiros", todos riem, provavelmente da insegurança infundada que gerou tanta dúvida. Em seguida, a aluna $\mathrm{C}$, que 
defendia esta opção, sentindo-se amparada pela professora, passa a explicar com maior clareza o que entende pela expressão. Neste, como em outros momentos, a professora representa a intervençāo conciliadora, apaziguadora, daquele que detém o poder de estipular verdades. Contudo, este papel - continuamente reiterado pelas instituiçōes de ensino - pode ser exercido de forma critica. Com este objetivo em mente, a professora procura estimular propostas e argumentos e, sempre que possivel, evita fornecer respostas prontas. Hipóteses tradutórias e incertezas devem ser manifestadas, e tempo adicional é dado para que sejam solucionadas as dúvidas que dependam de pesquisa.

Percebe-se que a discussāo em pequenos grupos limita a intervençāo da professora nos momentos em que o consenso nāo é possivel. Que os grupos decidam sobre a necessidade, ou não, de ajuda, nos parece uma prática saudável. Todavia, após a leitura das gravaçōes, temos a sensação de que, no decorrer da discussão, a presença da professora poderia ter agilizado o trabalho, principalmente quando um conflito envolvendo entendimento ou escolha de palavra perdurava. É possivel, porém, que o tempo gasto aparentemente de forma injustificada tenha sido benéfico, no sentido de ter permitido o confronto das várias hipóteses e a delimitação mais clara das dúvidas em questão, ou mesmo no sentido de estar propiciando a criação de mecanismos que futuramente agilizarão as discussōes.

\section{Contribuições para o ensino de Prática de Tradução}

Nossa meta de examinarmos a situaçāo de ensino-aprendizagem da tradução por meio de depoimentos e gravaçōes, de fato, levou à confirmação de que a sala de aula engloba tantos aspectos, tão ricos e diversos, que seu estudo é inesgotável. Isso nos auxiliou a tecer reflexōes que muito nos elucidam quanto ao nosso objetivo de formar profissionais competentes e conscientes de seu oficio.

A partir de nossa análise, constatamos que as consideraçōes que fizemos na presente pesquisa corroboram questōes centrais levantadas em estudo anterior (CEPE, 1995). Neste último, 
propusemos examinar as dificuldades tradutórias de alunos de Prática de Tradução da PUC-SP pela análise das traduções por eles produzidas e entregues para serem avaliadas pela professora. Nossa principal contribuição, então, foi pôr em evidência o vinculo vital que existe entre teoria e prática de tradução sugerindo que, subjacente às dificuldades tradutórias, encontra-se uma série de conceitos, a nosso ver equivocados, sobre o processo de ler, escrever e traduzir. A pesquisa que ora desenvolvemos se revelou extremamente produtiva ao confirmar esta descoberta por meio de outros instrumentos, isto é, do entrecruzamento de vârios ângulos de observação.

Se nossa prioridade não é tecer generalizações, contudo acreditamos que é válido fazer algumas afirmaçōes a respeito dos pressupostos e atitudes dos estudantes de Tradução da PUCSP. Em particular os alunos "iniciantes" mostraram que nāo estāo preparados para despender o tempo necessário para a elaboraçāo de uma tradução, pois lhes falta a iniciativa para realizar pesquisa em materiais de referência ou junto a consultores; que nāo estāo familiarizados com o processo de ouvir e julgar opções alheias; que têm dificuldade para expressar argumentos que justifiquem suas soluçōes; que nāo se sentem autores do texto que traduzem e crêem na imparcialidade de suas escolhas e; que tendem a acatar as sugestōes da professora como opçōes corretas e inquestionáveis.

As graduandas mais experientes, por sua vez, registraram em seus diários atitudes diferentes, sendo mais autônomas e confiantes em sua capacidade de resolver impasses, mostrandose muito mais criticas em relação a todo o processo. Não se sabe, contudo, se estas atitudes foram desenvolvidas nos semestres anteriores ou se são resultado de outras variáveis. Seria, sem düvida, interessante ter gravado as discussōes desses grupos para examinar o intercâmbio de informaçōes, principalmente no que diz respeito aos procedimentos tradutórios empregados.

Um dado novo que o presente estudo propiciou envolve a figura do professor. Os diários analisados sugerem que a própria professora mostra alguma insegurança sobre a eficácia do método que adota, do ponto de vista do encaminhamento que dá às solicitaçōes dos alunos. Ela admite que, às vezes, fornece res- 
postas prontas, o que mina sua meta de dar aos futuros tradutores a oportunidade de exercer o espirito de investigação e a criatividade. Os alunos, por sua vez, não parecem criticos em relação ao papel da professora e os registros examinados nada afirmam a respeito. A falta de clareza sobre os critérios utilizados na orientação das dúvidas é um aspecto que precisa ser repensado, visando a melhoria do ensino da tradução.

Para concluir nosso trabalho (mas não o tema, evidentemente), gostariamos de assinalar que a pesquisa de base etnográfica que guiou nosso estudo nos brindou com uma percepção mais ampla e mais nitida da situação de ensino-aprendizagem em que estamos imersos. A sala de aula parece ter adquirido uma outra qualidade. Tomar emprestada, por alguns instantes, a máscara do outro é um exercicio inesquecivel de renovação, mas ao retornar à nossa, vaza um olhar que brilha com outra intensidade, e que põe tudo que nos cerca agradavelmente sob suspeita.

\section{Agradecimentos}

Agradecemos ao Prof. Dr. Lynn Mário Menezes de Sousa, da USP, por ter despertado nosso interesse para a pesquisa etnográfica (e pelos seguidos empréstimos de textos da área) e à Profa. Walquíria Montemór e às alunas de Prática de Tradução do primeiro semestre de 1996 por sua valiosa contribuição para este estudo.

\section{Referências Bibliográficas}

ALLWRIGHT, D. \& BAILEY, K. (1991) Focus on the language classroom. Great Britain, Cambrige University Press.

ARROJO, R. (1986) Oficina de tradução. A teoria na prática. São Paulo, Ática. (1993a) A tradução passada a limpo e a visibilidade do tradutor. In: Traduçāo, Desconstrução e Psicanálise. Rio de Janeiro, Imago. 
- (1993b) Desconstrução, psicanálise e o ensino da tradução.

In: Tradução, Desconstrução e Psicanálise. Rio de Janeiro, Imago.

(1994) Ensino, conscientização politica e pós-modernismo.

In: Trabalhos em Lingüistica Aplicada n. 23.Campinas, UNICAMP/IEL. CAMPOS, G. (1986) O que é tradução. São Paulo, Brasiliense.

CAVALCANTI, M. C. e MOITA, L. (1991) Implementaçāo de pesquisa na sala de aula de linguas no contexto brasileiro. In: Trabalhos em Lingüistica Aplicada n. 17. Campinas, UNICAMP, p.133-44.

DARIN, L (1995) A teoria e a prática da tradução: um vínculo indissociável. Pesquisa não publicada apresentada à Comissão de Ensino e Pesquisa da PUC-SP. São Paulo.

ERICKSON, F. (1984) What makes school Ethnography 'ethnographic'? In: Anthropology and Education Quarterly, v. 15, USA.

FROTA, M. P. e Martins, M. (s/d) Reflexões sobre a avaliação em cursos de tradução. Rio de Janeiro, PUC-RJ. Pesquisa não publicada.

LIER, L. (1989) Ethnography: bandaid, bandwagon, or contraband? In: Research in the Classroom. London, Modern English Publications.

MENEZES DE SOUZA, L. M. e GRIGOLETO, M. (1994) Toward autonomy in teacher education: bridging the gap between the University and the Secondary State School. In: Autonomy in the Classroom. Porto Alegre, Editora da UFRGS.

QUENTAL, R. F. (1995) A dicotomia tradicional teoria/prática no ensino de tradução: suas manifestações, sua matriz teórica e seus efeitos para a formação de tradutores. Dissertação de Mestrado. Campinas, UNICAMP.

SNYDERS, G. (1978) Para onde vão as pedagogias não-diretivas? Lisboa, Moraes.

WATSON-GEGEO, K. A. (1988) Ethnography in ESL: defining the essentials. In: Tesol Quarterly, v. 22. 